
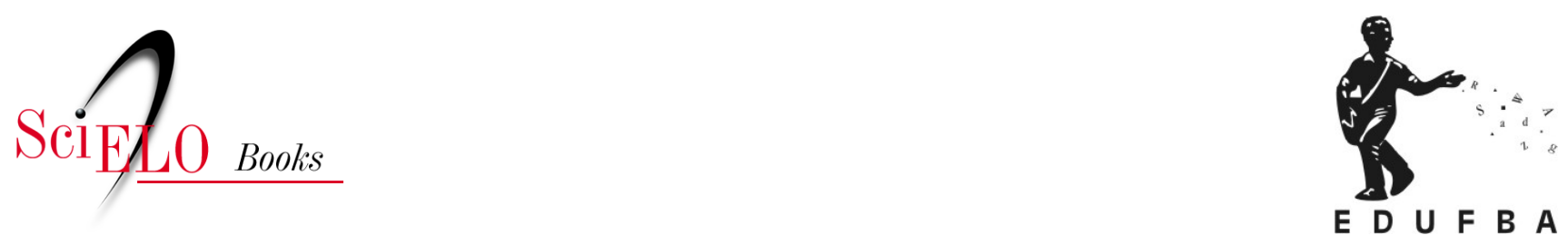

\title{
Capoeira uma história
}

\author{
Hellio Campos
}

\section{SciELO Books / SciELO Livros / SciELO Libros}

CAMPOS, H. Capoeira uma história. In: Capoeira regional: a escola de Mestre Bimba [online]. Salvador: EDUFBA, pp. 30-36. ISBN 978-85-232-1727-3. Available from: doi: 10.7476/9788523217273.0005. Also available in ePUB from: http://books.scielo.org/id/p65hq/epub/campos-9788523217273.epub.

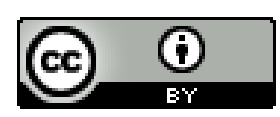

All the contents of this work, except where otherwise noted, is licensed under a Creative Commons Attribution 4.0 International license.

Todo o conteúdo deste trabalho, exceto quando houver ressalva, é publicado sob a licença Creative Commons Atribição 4.0. 


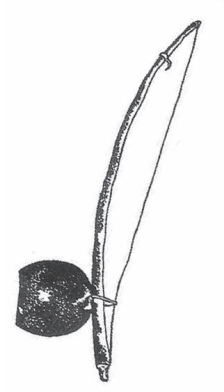

Capoeira uma história

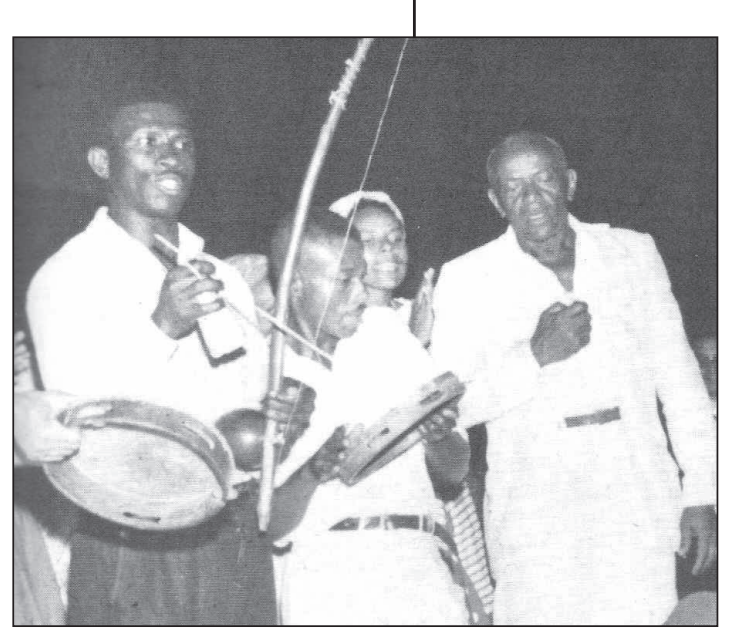


\} \begin{array} { l } { \text { ma compreensão adequada do fenômeno da capoeira exige sua investigação em } } \\ { \text { partes encadeadas, cujos fatos aparecem entrelaçados, daí a intenção de clarificá } } \end{array} -los e descrevê-los, contextualizando-os historicamente. Os episódios aqui relatados estão baseados em argumentos de vários estudiosos do assunto, os quais nos remetem a análises aprofundadas, à geração de novas idéias e ao estabelecimento de nexos.

\section{CAPOEIRA: UMA TRAJETÓRIA DE RESISTÊNCIA}

A escravidão é uma instituição muito antiga, que data dos primórdios da humanidade, porém foi no século XVI que o tráfico de escravos conformou-se como um negócio organizado, sistemático e vultoso, que representava enormes riquezas, principalmente depois que os portugueses criaram uma rota envolvendo os continentes europeu, africano, americano e, posteriormente, asiático, transformando, então, milhões de negros, em lucrativa moeda de troca e fácil riqueza.

Esses negros eram transportados nos porões dos chamados navios negreiros ou tumbeiros, em condições bastante precárias e subumanas, motivo pelo qual eram muitos os que sucumbiam, por não aguentarem os rigores de uma viagem longa, sendo acometidos de doenças em virtude dos maus-tratos.

Chegando ao Novo Mundo, eram vendidos e na sua maioria trocados por mercadorias como açúcar e fumo. Rego refere-se ao assunto da seguinte maneira: "argumenta-se que a sobrevivência das primeiras engenhocas, o plantio da cana de açúcar, do algodão, do café e do fumo foram os elementos decisivos, para que a metrópole enviasse para o Brasil os primeiros escravos africanos" (1968, p. 9).

Areias, referindo-se também ao tráfico dos escravos, diz que:

Eram os negros tirados do seu habitat natural, colocados nos porões dos navios e levados para os novos horizontes recém-descobertos pelas grandes potências européias da época. Chegando à nova terra, eram repartidos entre os senhores, marcados a ferro em brasa como gado e empilhados na sua nova moradia: as prisões infectadas das senzalas (1983, p.10).

No entanto, o escravo era uma ótima mercadoria e seus compradores tinham a expectativa de que esta se pagasse em cinco anos, através das jornadas criminosas de trabalhos forçados. A expectativa média de vida dos escravos, porém, girava por volta dos sete anos, devido à precariedade das moradias e à exígua alimentação. 
No negócio da troca de mercadorias, por ser altamente rentável e sendo o escravo uma mercadoria barata na África, os senhores de engenho eram forçados a comprar, a cada vez, mais escravos, a ponto de serem até chantageados, pois, caso não os comprassem, não poderiam vender o açúcar. Pressionados, foram impelidos a comprar grande número de escravos, consequentemente endividando-se.

Contudo, os negros, considerados "peças da África”, custavam barato e, por esse motivo, eram descartáveis. Até mesmo os portugueses menos favorecidos economicamente, reconhecidos como pobres, podiam ter pelo menos um escravo. Quando não os possuíam, isso era motivo de humilhação e, muitas vezes, antecipavam seu retorno a Portugal.

Ao chegarem ao Brasil, os negros escravos eram desembarcados nos portos, pagandose por eles impostos, como qualquer outra mercadoria. Em seguida, ficavam expostos à venda nos mercados, onde os senhores e senhoras os examinavam, escolhendo de acordo com os ofícios e serviços a que seriam submetidos. Nessa escolha, tinha-se preferência por determinado tipo físico, pelo aspecto de saúde e até pela região de origem.

Os negros eram usados nos mais diversos tipos de serviços: plantadores, roceiros, semeadores, moedores de cana, vaqueiros, remeiros, mineiros, artífices, pescadores, lavradores, caldeireiros, marceneiros, pedreiros, oleiros e ferreiros; eram domésticos, pajens, guarda-costas, capangas, capatazes, feitores, capitães-do-mato e até carrascos de outros negros.

Os escravos estavam por toda parte, nos setores urbano e rural; viviam nas ruas, nos mercados, portos, mercearias, residências, palácios, repartições, engenhos, senzalas etc.

Com os escravos participando ativamente da sociedade, esta foi aos poucos absorvendo sua cultura: folguedos, danças, culinária e crenças. Perguntamos: o que seria do Brasil, hoje, sem o legado do povo africano?

Machado, referindo-se aos negros, às questões culturais e à forma de transmissão do conhecimento, assim se expressa:

\begin{abstract}
Na verdade, os negros introduzidos no Brasil pertenciam a diversas etnias que provinham das mais variadas regiões da África. Entretanto, havia fortes pontos em comum. As suas religiões, os seus costumes, quaisquer que fossem, mantinham profunda relação com certas formas de família e organização clânica. Fiéis à cultura dos seus antepassados, os valores de sua identidade foram transferidos dos mais velhos para os mais novos e apreendidos facilmente pelas crianças. São valores de uma identidade coletiva que faz parte de uma herança comum como padrão de comportamento. Padrão este que está contido no pensamento simbólico e nas ações em quase todos os aspectos das suas atividades cotidianas, ressaltando com mais profundidade nas comunidades de candomblé (1989, p. 71).
\end{abstract}

Ainda sobre a participação do negro na sociedade brasileira, com ênfase no início do século XIX, Soares assim se reporta:

Nessa época crítica da formação do Estado Nacional, como expressão combativa da massa escrava negro -africana, que monopolizava o trabalho na cidade, a capoeira foi o canal expressivo da resistência escrava, e por isso vítima permanente da violência senhorial e policial $(1994$, p. 7).

Nas duas citações acima, observamos de pronto a mesma visão da contribuição do negro escravo para a formação da sociedade brasileira e sua participação cotidiana, tanto na cidade como no meio rural, influenciando decisivamente no aspecto cultural e de resistência. 
Machado (1989) destaca o candomblé e Soares (1994) a capoeira como focos importantes de resistência. Não se trata, entretanto, de aspectos culturais isolados, mas, sim, de um conjunto de características que, baseado nas organizações familiares e de sobrevivência, foi transmitido pela oralidade, dos mais antigos para os mais jovens, os quais perpetuaram sua cultura, adaptada ao Novo Mundo, até os dias de hoje.

\section{ORIGEM E EVOLUÇÃO DA CAPOEIRA}

Existem controvérsias sobre a origem da capoeira e várias são as hipóteses, porém duas fortes correntes se confrontam: "uma afirma que a capoeira teria vindo para o Brasil trazida pelos escravos, e a outra considera a capoeira como uma invenção dos escravos no Brasil" (CAMPOS, 1990, p. 17).

Rego, reportando-se ao período da escravatura no Brasil, diz ser impossível precisar quando chegaram ao Brasil os primeiros escravos (1968, p. 10). A grande dificuldade em obter tal afirmação deve-se principalmente ao conselheiro Ruy Barbosa que, quando Ministro da Fazenda do Governo Deodoro da Fonseca, mandou queimar toda a documentação referente à escravidão negra no Brasil. Sobre este assunto, Rego, citando Ruy Barbosa, manifesta-se dizendo que, infelizmente, o conselheiro Ruy Barbosa, por essa ou por aquela razão, nos prestou um mau serviço ao tomar aquela atitude (1968, p. 9), destacando o seu ato:

Considerando que a nação brasileira, pelo mais sublime lance de sua evolução histórica, eliminou do solo da pátria a escravidão - a instituição funestíssima que por tantos anos paralisou o desenvolvimento da sociedade, inficionou-lhe a atmosfera moral; considerando que a República está obrigada a destituir esses vestígios por honra da pátria, e em homenagem aos nossos deveres de fraternidade e solidariedade para com a grande massa de cidadãos que pela abolição do elemento servil entraram na comunhão brasileira; resolve:

$1^{\circ}$ - Serão requisitados de todas as tesourarias da Fazenda todos os papéis, livros e documentos existentes nas repartições do Ministério da Fazenda, relativos ao elemento servil, matrícula de escravos, dos ingênuos, filhos livres de mulher escrava e libertos sexagenários, que deverão ser sem demora remetidos a esta capital e reunidos em lugar apropriado na recebedoria.

$2^{\circ}$ - Uma comissão composta dos Srs. João Fernandes Clapp, presidente da confederação abolicionista, e do administrador da recebedoria desta capital, dirigirá a arrecadação dos referidos livros e papéis e procederá à queima e destruição imediata deles, o que se fará na casa de máquina da alfândega desta capital, pelo modo que mais conveniente parecer à comissão.

Capital Federal, 5 de dezembro de 1890 - Ruy Barbosa.

Como é realmente difícil afirmar qual a verdadeira origem da capoeira, várias hipóteses são discutidas, ainda que não se possa chegar a um denominador comum fidedigno. Waldeloir Rego defende a tese de que a capoeira foi inventada no Brasil, pelos descendentes afro-brasileiros (1968, p. 31), reforçando a concepção de Soares, que insiste na idéia de que a capoeira foi uma invenção dos escravos no Brasil, justificando as peculiaridades da escravidão urbana, mesmo majoritariamente por africanos (1994, p. 25).

Sobre o assunto, Araújo, referindo-se à historicidade da capoeira, argumenta existir um "número significativo de dúvidas" que cresce com o passar do tempo. E chama a atenção 
para a "carência de um maior rigor científico" nessa questão. Observa, ainda, a necessidade de maior aprofundamento em campos de estudos diversificados (1995, p. 3).

Outras discussões aparecem quando se trata do termo capoeira. O vocábulo capoeira tem sido utilizado por vários estudiosos, sendo registrado pela primeira vez em 1712, por Rafael Bluteau (1712, p. 129), seguido por Moraes, em 1813.

A primeira proposição de que se tem notícia é a de José de Alencar, em 1865, na primeira edição de Iracema. Sugere Alencar, para o vocábulo capoeira, o tupi Caa-Apuam-era, traduzido por "ilha de mato já cortado". Segundo Rego, Henrique Beaurepaire Rohan (1879) propôs o tupi Co-puera, significando "roça velha" (1968, p. 17); já, para Macedo Soares (1880), o vocábulo vem simplesmente do guarani Caápuêra, "mato que foi", atualmente mato miúdo que nasce no lugar do mato virgem que se derrubou; J. Barbosa Rodrigues (1887), no século passado registrou em seu livro Paranduba Amazonense, a forma Caapoêra; e para o Visconde de Porto Seguro, o termo certo é Capoêra.

Ainda existem outros argumentos sobre o vocábulo, porém duas citações chamam a atenção dos estudiosos: a primeira diz respeito ao nome de uma ave parecida com uma perdiz que vive em bandos, sendo oriunda do Brasil e do Paraguai. Esta ave, chamada de capoeira (Odontophores Capueira-six), também é conhecida por Uru. A segunda relaciona o termo ao vocábulo português Capoeyra que significa "cesto para guardar capões", muito utilizado pelos escravos vendedores de galinhas.

Entende-se também capoeira como um jogo atlético de ataque e defesa cheio de mandinga, malandragem e muito eficiente. Para Soares a "capoeira era uma espécie de jogo atlético, que consistia em rápidos movimentos de mãos, pés e cabeça, em certas desarticulações do tronco, e particularmente na agilidade de saltos para frente, para trás, para os lados, tudo em defesa e ataque, corpo a corpo" (1994, p. 13).

Semanticamente falando, o vocábulo comporta várias acepções, conforme consta dos principais dicionários da língua portuguesa.

Para Aurélio Buarque de Holanda Ferreira:

Capoeira $^{1}$. s.f. Gaiola grande ou casinhola onde se criam e alojam capões e outras aves domésticas. 2. P. ext. O conjunto de aves domésticas. 3. P. ext. ao conjunto de aves domésticas de uma criação.

$\underline{\text { Capoeira }}^{2}$. [Do tupi kapuéra] S.f. Bras. 1. Terreno em que o mato foi roçado e/ou queimado para o cultivo da terra ou para outro fim. "A CAPOEIRA (mata que foi)...2. Mato que nasceu nas derrubadas de mata virgem. 3. V. uru ${ }^{1}$. 4. Cap. Jogo atlético constituído por um sistema de ataque e defesa, de caráter individual e de origem folclórica genuinamente brasileira, surgido entre os escravos bantos procedentes de Angola no Brasil colônia, e que, apesar de intensamente perseguidos? até as primeiras décadas do séc.XX, sobreviveu à repressão e hoje se amplia e se institucionaliza como prática desportiva regulamentada:

Capoeirada. s.f. Brás. Cap. 1. Conjunto de capoeiristas. Obsol. Designação das maltas de capoeiristas que no séc. XIX provocaram desordens e promoviam agressões em desfiles, festas, aglomerações etc.

Capoeiragem. s.f. Bras. 1. Sistema de lutas dos capoeiras. 2. Vidas de capoeira.

Capoeirista. s. 2.g. jogador de capoeira (1986, p. 344).

Segundo Antônio Houaiss: 
Capoeira s.f. 1 luta introduzida pelos escravos bantos. 2. terreno desmatado. 2.1 mato que ali cresce. 3. gaiola para aves domésticas. Capoeirista s.2g. Capoeiragem s.f. (2003, p. 94).

Para Caldas Aulete:

Capoeira $^{1}$ (ca.po:ei.ra) sf. 1 Gaiola grande us. para criar capões ${ }^{1}$ e outras aves domésticas. 2 Conjunto dessas aves.

Capoeira ${ }^{2}$ (ca.po:ei.ra) Bras. sf. 1 Jogo atlético criado por escravos, tb. us. como técnica de ataque e defesa, em que se executavam golpes com as pernas. 2 Terreno de mato roçado. s2g. 3 Ver capoeirista.

Capoeirista (ca.po:ei.ris.ta) s2g. Pessoa que joga capoeira; CAPOEIRA (2004, p. 139).

É deveras relevante entender como os mestres conceituam a capoeira. A seguir, citamos trechos de uma reportagem veiculada na Revista Capoeira (1998, p. 28-30), cujo assunto reflete a nossa preocupação e é pertinente para entendermos com clareza o que pensam os referidos mestres. Nessa reportagem, que conta com a participação de vinte mestres de diferentes correntes, eles tentam responder a uma questão que tanto intriga os capoeiristas: o que é a Capoeira? Algumas das respostas são aqui transcritas:

Mestre Baiano Anzol, Rio de Janeiro/RJ: A Capoeira é um jogo de movimentação contínua, de velocidade, sem rigidez de movimentos. É na ladainha que mostra sua poesia e a força espiritual de seus praticantes. Diferencia-se, assim, das demais lutas, pela musicalidade contida no seu ritmo e no seu axé. Capoeirar não é uma simples sequência de golpes e de saltos encadeados. É mais do que isso: é sentir a emoção de participar harmonicamente da troca de energias, contidas no movimento do corpo associado à fluidez da alma.

Mestre Canelão, Natal/RN: Capoeira, para mim, é coisa muito pessoal. Cada mestre tem a sua opinião. Eu vivo de Capoeira e ela é tudo: minha vida, minha filosofia.

Mestre Camisa, Rio de Janeiro/RJ: Capoeira é uma arte que engloba várias artes em uma só arte: é um trabalho, uma luta, uma arte, uma dança. É poesia. Tudo isto tem seu momento, ou seja, ela é o que o momento determinar. É luta nacional brasileira, filosofia de vida. Como consequência, o capoeira compreende a vida de uma maneira diferente: com mais jogo de cintura. Dessa forma consegue melhorar suas dificuldades e vivenciar com mais objetividade seus sentimentos.

Mestre Moraes, Salvador/BA: Capoeira é, para mim, a fusão de corpo e mente. Através da Capoeira pode-se trabalhar o corpo e estruturar a mente, para um entendimento da sociedade em que se vive.

Mestre Pinheiro, Juiz de Fora/MG: A Capoeira, para mim, é tudo. É uma arte, é dança, é uma ginástica, é cultura, é uma forma de defesa pessoal, é uma filosofia de vida. Não se pode falar de capoeira sem saber a sua história e seus fundamentos.

Mestre Burguês, Curitiba/PR: A Capoeira é uma luta, arte, cultura, folclore, poesia, esporte, filosofia de vida, liberdade, expressão corporal, profissão, educação física; tradição de povo e muito mais: é o ar que respiro.

Percebe-se que o conceito de capoeira é muito amplo, e cada praticante, cada mestre, o define diferentemente, considerando principalmente a academia ou grupo a que pertence, levando-se em conta ainda qual o propósito da sua prática.

Analisando os depoimentos dos vinte mestres e de outros com os quais mantivemos conversas informais, ao longo de trinta anos, pudemos observar o quanto a capoeira representa na vida dessas pessoas. São comuns nesses testemunhos afirmações de que a capoeira é algo sobrenatural, algo mágico, que estimula a transcendência, passando mesmo a ser encarada como uma filosofia de vida e um jeito de ser. 
Normalmente, esses mestres falam da capoeira como uma arte, poesia, luta, folclore, expressão corporal, harmonia, equilíbrio, espiritualidade, emoção, jogo de cintura, liberdade, enfim, muitos predicados que repercutem no modo de vida de cada um deles.

Nas últimas duas décadas, a capoeira evoluiu muito, tanto em nível nacional como internacional, e cresceu desordenadamente, sem uma sistematização condigna com a sua magnitude e alcance, a ponto de muitos mestres se reportarem ao assunto dizendo que a capoeira não somente cresceu e evoluiu, mas acima de tudo inchou.

A capoeira saiu dos guetos, do terreno baldio, do quintal e conquistou a rua, a praça, a academia, o clube, o teatro, a escola e a universidade; conquistou a sociedade brasileira e, atualmente, está espalhada no mundo inteiro. Mestre Suassuna, em 1987, no I Seminário de Capoeira da UFBA, afirmou que "[...] a capoeira não pertence mais à Bahia, ela pertence ao Brasil e ao mundo"1.

Na atualidade, a capoeira está estruturada em grupos, os quais são dirigidos por um mestre que é o responsável pela organização, controle e filosofia. Seguindo a hierarquia, encontram-se os contramestres ${ }^{2}$, um aluno formado, e outros graduados.

Existem, também, outros órgãos públicos e privados que interferem na macro-organização da capoeira, a exemplo da Confederação Brasileira de Capoeira e suas filiadas, as federações estaduais, cujas áreas de atuação praticamente se restringem a incentivar, orientar e promover eventos esportivos, destacando-se as competições do gênero.

Outras sociedades, como as associações de classe, destacando-se a Associação Brasileira dos Professores de Capoeira (ABPC), a Associação Brasileira de Capoeira Angola (ABCA) e a Fundação Mestre Bimba (FUMEB), além da finalidade de congregar a categoria, têm uma preocupação com o resgate das tradições, o aprofundamento dos estudos, a investigação, a discussão, o debate e a salvaguarda da capoeira de sua descaracterização.

Cabe citar que a capoeira está fortemente presente nas instituições de ensino, nas escolas de ensino fundamental e médio e nas universidades.

\footnotetext{
${ }^{1}$ O I ${ }^{\circ}$ Seminário de Capoeira da UFBA foi realizado em 1987, sendo o autor, na ocasião, coordenador dos trabalhos.

${ }^{2}$ Denominação dada a um integrante do grupo de capoeira imediato ao mestre.
} 